\title{
A RELAÇÃO ENTRE GÊNERO E EXPRESSÃO VERBAL: UMA ABORDAGEM DISCURSIVA PARA A MANIFESTAÇÃO DA FUTURIDADE
}

\section{Marcos Rogério CINTRA*}

- RESUMO: Neste artigo propomos uma descrição das formas verbais de futuro em articulação com o funcionamento discursivo do gênero em que se manifestam. Nosso enfoque concentra-se nas formas verbais que atualizam a expressão do futuro do presente no gênero radiofônico notícia com entrevista. Descrevemos a estruturação desse gênero em termos de recursos estratégicos (DIJK, 1990, 2010) que visam aumentar a percepção factual das informações veiculadas. Mostramos que o fato de as notícias com entrevista serem estrategicamente elaboradas implica não apenas que a forma de apresentação das informações é esquematicamente concebida para favorecer a interação, mas também que essa estruturação discursiva motiva a elaboração linguística do conteúdo da informação. Nossa investigação permite constatar que as formas de futuro do presente podem ser discursivamente descritas e distribuídas em decorrência de três diferentes eventos prospectivos que integram: eventos programados, eventos da interação em curso e eventos procedimentais. Além disso, nosso estudo mostra a viabilidade de se estabelecer uma relação entre gênero discursivo e expressão verbal, visto que algumas formas de futuridade, como o futuro perifrástico progressivo, são favorecidas por práticas discursivas como as notícias com entrevista.

- PALAVRAS-CHAVE: Futuro do presente. Gênero discursivo. Notícias com entrevista. Estruturação estratégica.

\section{Introdução}

Em grande parte das investigações empreendidas sobre a futuridade verbal, a vinculação da expressão do futuro a um gênero discursivo não é avaliada como fundamental para descrever as suas formas de manifestação. Geralmente a noção de gênero serve apenas como parâmetro metodológico para a delimitação de um corpus de análise, relegando a um segundo plano as relações que se instanciam entre a estruturação do discurso e a materialização da futuridade. No cenário de pesquisas desenvolvidas acerca da futuridade verbal no português brasileiro (PB), por exemplo, podemos apreciar um relevante e variado conjunto de estudos que tende a abordar a expressão do futuro como uma questão linguística de

* UFVJM - Universidade Federal dos Vales do Jequitinhonha e Mucuri. Faculdade Interdisciplinar em Humanidades. Diamantina - MG - Brasil. 39.100-000 - marcoscintra@ufvjm.edu.br 
natureza fundamentalmente sintático-semântica (BALEEIRO, 1988; SILVA, M., 2000; OLIVEIRA, 2006; POPLACK; MALVAR, 2007; entre outros). Não são comuns, nesse sentido, abordagens que inscrevam a futuridade também como um objeto de investigação textual.

Neste artigo, por outro lado, propomos que a futuridade pode ser discursivamente descrita, não apenas no sentido de que o gênero pode propiciar a ocorrência de determinadas formas verbais, mas também no sentido de que o funcionamento discursivo - efetivado na ação conjunta de atores sociais empenhados na construção interacional de sentidos — permite que sejam reconhecidas regularidades na distribuição das formas verbais na materialidade textual. Trata-se de um tipo de enfoque ainda lacunar na literatura sobre o assunto e, dessa forma, procuramos contribuir para essa discussão. Para abordar a relação entre gênero e expressão verbal, focalizaremos as formas verbais que atualizam a expressão do futuro do presente num gênero ainda pouco investigado, as notícias radiojornalísticas com entrevista. ${ }^{1}$

Na grande maioria das investigações recentes sobre a expressão verbal da futuridade no PB (BALEEIRO, 1988; SILVA, M., 2000; SILVA, A., 2002; OLIVEIRA, 2006; POPLACK; MALVAR, 2007; entre outros), não se encontram, por exemplo, descrições sobre a realização do futuro perifrástico progressivo, formado pela

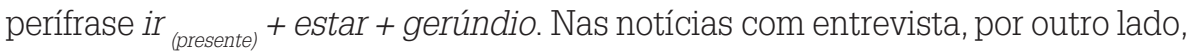
esse tipo de ocorrência de futuro progressivo é percentualmente significativo, destacando-se no conjunto de possibilidades de variação das formas de futuro nesse gênero. Esse fato, como argumentaremos no decorrer do trabalho, constitui evidência favorável de que determinados modos de expressão verbal são propiciados ou motivados em razão das contingências enunciativas do gênero em que se materializam.

Nosso universo de investigação compõe-se por 22 informes com entrevista, selecionados dos radiojornais Desperta Rio Preto (DRP), Jornal do Servidor Público Municipal (JSPM) e Jornal do Trabalhador (JT), da cidade de São José do Rio Preto - SP. ${ }^{2}$ Trata-se de radiojornais diários que divulgam fundamentalmente notícias de interesse público, centradas em acontecimentos e eventos de relevância geral acerca da cidade de São José do Rio Preto e adjacências. Diferentemente do gênero notícia e do gênero entrevista em

Deve-se ressaltar, a esse respeito, que já foram bastante investigadas as entrevistas em debates radiofônicos (ALMEIDA; GERAB, 2006; AQUINO, 2008; entre outros), mas pouco enfoque foi dado às entrevistas que integram as notícias como uma de suas partes, constituindo casos de "hibridação" ou "hibridização" de gêneros midiáticos (PINHEIRO, 2002).

2 Para garantir a padronização do material transcrito e fornecer indicações da situação interativa, tomou-se como referência o "Manual do Sistema de Transcrição de Dados", elaborado por Tenani e Gonçalves (2003) para o atualmente denominado Projeto ALIP ("Amostra Linguística do Interior Paulista" - Banco de Dados Iboruna - UNESP/S. J. Rio Preto). O conjunto completo das notícias radiojornalísticas com entrevista transcritas encontra-se em Cintra (2011). 
sentido estrito (PRADO, 1989), os informes selecionados constituem um gênero híbrido, que aqui será denominado notícia com entrevista ${ }^{3}$

Tendo em vista essas considerações, este artigo divide-se em quatro partes. Na primeira delas, revisitamos alguns estudos que tratam da expressão do futuro do presente, ressaltando que na literatura sobre o assunto mesmo trabalhos recentes tendem a enfocar a futuridade como uma questão de natureza fundamentalmente sintático-semântica, colocando em um segundo plano as relações que se estabelecem entre gênero e manifestação verbal. Em consequência, muitas dessas investigações não conseguem identificar ocorrências de futuridade cuja manifestação se vincula a determinados modos de interlocução verbal. Em seguida, discutimos que o gênero notícia com entrevista propicia a atualização de formas perifrásticas progressivas de futuridade de acordo com o seu funcionamento interacional estratégico, apresentando uma descrição dos principais aspectos textuais e discursivos que permitem caracterizar essa forma de interlocução. Na terceira parte, por sua vez, interpretamos a distribuição das formas verbais de futuro em decorrência dos diferentes eventos prospectivos que integram, isto é, mostramos que a distribuição das formas de futuro pode ser correlacionada a eventos discursivos que permitem caracterizar o funcionamento enunciativo das notícias com entrevista. Por fim, expomos algumas considerações finais, enfatizando que a investigação da relação que se estabelece entre gênero e expressão verbal pode oferecer uma explicação para o fato de a materialização de algumas formas de futuridade, como o futuro perifrástico progressivo, ser favorecida por práticas discursivas como as notícias com entrevista.

\section{Gênero discursivo e expressão verbal da futuridade}

A coexistência de formas perifrásticas e sintéticas relacionadas ao domínio da futuridade, diacronicamente documentadas na evolução das línguas neolatinas, evidencia uma codificação dinâmica relacionada ao processo de analiticidade, em que formas sintéticas e analíticas alternam-se (COUTINHO, 2005, p.276-277; FLEISCHMAN, 1982a; KLAUSENBURGER, 2000; SILVA, R., 2006, p.143). A esse padrão cíclico de síntese de uma construção perifrástica inicial e consequente substituição por uma forma perifrástica emergente, ao longo do tempo, Castilho (1997, p.35) denomina "continuidade da inovação".

Nas notícias com entrevista selecionadas, o gênero entrevista encontra-se imbricado no gênero notícia que, por sua vez, materializa-se nos hipergêneros Desperta Rio Preto (DRP), Jornal do Servidor Público Municipal (JSPM) e Jornal do Trabalhador (JT). Esses radiojornais, assim como outras interações jornalísticas, comportam variadas práticas discursivas, podendo ser denominados hipergêneros. As notícias com entrevista são transmitidas ao vivo e representam um dos muitos gêneros que esses hipergêneros congregam. 
Os variados estudos que abordam a expressão verbal da futuridade no PB são, fundamentalmente, elaborações dessa premissa da continuidade de inovação na tentativa de descrever a distribuição das formas de futuridade, enfocando suas realizações mais destacadas. Essas pesquisas convergem para a constatação de que o futuro analítico formado por ir ${ }_{\text {(presente) }}+$ infinitivo suplantou sua forma concorrente sintética (BALEEIRO, 1988; SILVA, M., 2000; SILVA, A., 2002; OLIVEIRA, 2006; POPLACK; MALVAR, 2007; entre outros), que pode ser considerada uma das várias "camadas" (HOPPER, 1991) em que se desdobra o domínio da futuridade.

Baleeiro (1988), por exemplo, fundamentada em ocorrências do português culto falado em São Paulo (NURC-SP), e Ademar da Silva (2002), baseado principalmente em um conjunto de conversações telefônicas, constatam que a perífrase ir (presente) + infinitivo e o presente simples acompanhado de adjuntos adverbiais de tempo são formas consideravelmente mais produtivas que o futuro sintético. O estudo de Oliveira (2006), que corrobora esses resultados, é bastante ilustrativo por mostrar que o emprego da forma perifrástica de futuro é uma mudança que se acelera rapidamente. Ao comparar a distribuição do futuro sintético, do futuro perifrástico ir (presente) + infinitivo e do presente simples entre as décadas de 1970 e 1990, com base em amostras de diálogos entre informante e documentador (DIDs - RJ e Salvador) do projeto NURC, Oliveira (2006) atesta a redução do futuro sintético, o aumento de ir (presente) + infinitivo e a estabilização do presente: futuro sintético (25/11\%), ir (presente) + infinitivo (164/73\%), presente simples (37/16\%) na década de 1970 (226 ocorrências); futuro sintético (5/3\%), ir (presente) + infinitivo (137/82\%), presente simples (25/15\%) na década de 1990 (167 ocorrências).

No conjunto de notícias com entrevista analisadas, foram identificadas quatro principais possibilidades de manifestação verbal do futuro do presente: ir ${ }_{\text {(presente) }}+$

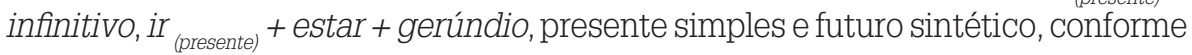
demonstram (1), (2), (3) e (4), respectivamente.

(1) S.S.: e no programa de hoje nós vamos conversar com a diretora do Sindicato e Conselheira Municipal de Saúde S. L. B... (JSPM-02:02)

(2) R.: isso mesmo... os diretores vão tá indo até as empresas onde vão tá entregando as carteirinhas pros associados que já se recadastraram e os novos... fazendo seu recadastramento (JT-03:29)

(3) J.: com certeza... na sexta-feira aqui no caminhão sobe no palco éh:: Tinoco e Gentil Rossi fazendo um show ah:: da música sertaneja (JT-04:34)

(4) agora a garantia do registro é uma garantia tanto pro empregado principalmente como pro próprio empregador é uma garantia que amanhã ou depois ele não sofrerá um processo (JT-11:83) 
A ordem de apresentação das formas verbais destacadas anteriormente (1 > 4) representa a sua distribuição quantitativa no corpus. As ocorrências em (1) e em

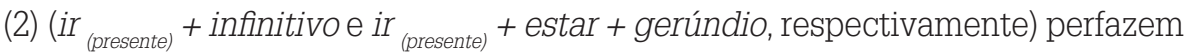
quase a totalidade dos dados e, por isso, são notadamente as perífrases mais relevantes para caracterizar a expressão verbal do futuro do presente nas notícias com entrevista. Embora as ocorrências em (3) e (4), presente simples e futuro sintético, apresentem menor expressividade quantitativa, ainda assim comportam certa recorrência. Considerando-se essas quatro formas de manifestação verbal do futuro do presente, pode-se propor a seguinte tabela:

Tabela 1 - Expressão do futuro do presente nas notícias com entrevista

\begin{tabular}{lc}
\hline \multicolumn{1}{c}{ Forma de manifestação } & Total \\
ir ${ }_{\text {(presente) }}+$ infinitivo & $162(62 \%)$ \\
ir $_{\text {(presente) }}+$ estar + gerúndio & $51(20 \%)$ \\
presente simples & $30(11 \%)$ \\
futuro sintético & $17(7 \%)$ \\
Total & 260 \\
\hline
\end{tabular}

Fonte: Elaboração própria.

A tabela 1 permite verificar que o futuro perifrástico progressivo corresponde ao segundo tipo mais significativo de manifestação da futuridade verbal nesse gênero. Essa constatação é bastante relevante, na medida em que se nota que mesmo investigações recentes sobre esse tema no PB não dão relevância a essa perífrase e, na maioria das vezes, tampouco apontam essa forma progressiva de futuro como uma possibilidade de variação entre os modos de expressão do futuro do presente.

É oportuno, neste momento, salientar que a delimitação do gênero notícia com entrevista, como materialidade textual e discursiva para o estudo das formas de futuridade, resulta de um longo processo investigativo em que se visou à identificação de situações de interação verbal que promovessem a ocorrência de formas de futuridade progressiva. Num processo de observação, ${ }^{4}$ que também

4 Deve-se mencionar, a esse respeito, que procedemos à observação de um amplo conjunto de textos, representativos de diversos gêneros da língua oral e escrita, até que se definissem as notícias com entrevista como materialidade empírica. No que concerne aos dados da língua falada, foram investigados os corpora Discurso \& Gramática (2007), NURC-SP (CASTILHO; PRETI, 1986, 1987) e IBORUNA (GONÇALVES, 2007). Com relação aos dados da língua escrita, foram investigadas: (a) 15 edições dominicais dos jornais rio-pretanos Bom Dia, DHoje e Diário da Região; (b) 5 edições das revistas Seven Nights, Social Light e Villa Redentora; (c) 300 redações de alunos do $3 .^{\circ}$ ano do Ensino Médio. Em vista dos objetivos desta pesquisa, no entanto, dentre esse 
envolveu a audição e a gravação de um vasto número de programas radiofônicos, verificou-se que as notícias com entrevista, extraídas de três radiojornais de relevância local e regional de São José do Rio Preto — os programas Desperta Rio Preto (DRP), Jornal do Servidor Público Municipal (JSPM) e Jornal do Trabalhador (JT) - constituem um tipo de interlocução em que as construções de futuro perifrástico progressivo se mostram quantitativamente relevantes, em comparação com outras situações interativas.

A seleção das notícias com entrevista, dentre os vários materiais pesquisados, permitiu atestar que, a depender do gênero em que se respalda a descrição da futuridade, as formas de futuro perifrástico progressivo são bastante reduzidas ou mesmo não ocorrem. Em outros termos, consideramos que existe uma relação entre a manifestação de algumas formas verbais e a natureza do discurso que as instancia. Essa constatação também pode ser corroborada pelo fato de os poucos estudos acerca das construções progressivas de futuridade relatarem dificuldade no estabelecimento de uma amostra significativa dessas formas perifrásticas. Em sua pesquisa de natureza sociolinguística, Santos (2008), por exemplo, tendo efetuado a coleta de dados, constatou que apenas $1 \%$ do total de formas de futuro correspondia

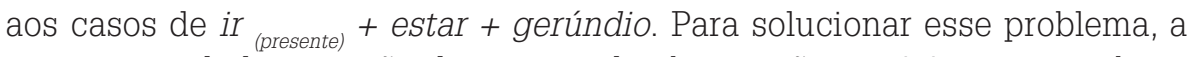
autora teve de lançar mão do recurso de observação participante com base em Sankoff (1988 apud SANTOS, 2008), coletando ocorrências que ouviu em diferentes situações interlocutivas para, então, reuni-las aos dados de que já dispunha. Chama a atenção, nesse sentido, que tenhamos coletado os dados de um único tipo de situação interlocutiva (as notícias com entrevista) e que o percentual do futuro perifrástico progressivo represente $20 \%$ do total de ocorrências comutáveis de futuro do presente.

A verificação de que o futuro perifrástico progressivo é uma forma de manifestação significativa nas notícias com entrevista desperta, naturalmente, o interesse por investigar os motivos de essa perífrase, pouquíssimo referida nos estudos que tratam da expressão da futuridade no PB, representar uma forma de manifestação destacada no domínio da futuridade. Em termos da abordagem que propomos, esse questionamento pressupõe que a organização global e a dinâmica interacional do texto noticioso com entrevista favorecem a ocorrência do futuro perifrástico progressivo, conforme discutiremos a seguir.

diversificado conjunto de dados pesquisados, não foram identificados gêneros que se mostrassem adequados à comprovação do pressuposto de que determinadas formas verbais são promovidas pelo discurso. Realizamos, então, a audição e gravação de programas de rádio que nos levaram, finalmente, às notícias com entrevista. 


\section{A dinâmica interacional do discurso noticioso e a expressão verbal do futuro do presente}

Apresentando uma abordagem pioneira no tratamento do discurso noticioso, Dijk $(1990,2010)$ argumenta que a estruturação desse discurso relaciona-se ao modo como se processa a informação tanto na produção como na compreensão da notícia. Embora o presente trabalho focalize um tipo de discurso noticioso diferente daquele pesquisado por Dijk $(1990,2010)$, partilhamos com esse autor a premissa de que a investigação do discurso noticioso permite reconhecer sua composição estratégica. ${ }^{5}$ Nesse sentido, consideramos que a expressão da materialidade textual está vinculada à composição da notícia. A caracterização do gênero notícia com entrevista como prática interacional pressupõe que a construção dos sentidos é efetivada na ação cooperativa de atores sociais discursivamente construídos e orientados pelas contingências e pelos propósitos da situação enunciativa.

O discurso noticioso com entrevista aqui analisado pode ser descrito como uma situação interacional cujo intuito fundamental consiste na divulgação de eventos planejados e de procedimentos que devem ser seguidos para a realização de algum serviço de interesse público. Em vista desse projeto de dizer, podem ser descritos como estratégicos os recursos que, ao estruturar esse tipo de discurso noticioso, contribuem para acentuar a percepção da natureza factual das informações, correspondendo a estratégias de persuasão do rádio-ouvinte. Dois desses recursos estratégicos são a composição híbrida das notícias com entrevista e o papel legitimador atribuído ao entrevistado.

O primeiro desses recursos refere-se à forma de apresentação das notícias. Nesse gênero, a notícia é realizada estrategicamente em dois planos complementares e integrados: o plano da sumarização e o plano da especificação. No plano da sumarização, o informe é apresentado como um tipo de resumo informativo e, no plano da especificação, como um relato jornalístico estendido desse resumo, sob a forma de uma entrevista. No desenvolvimento da situação interativa, o plano da sumarização recobre a abertura e o fechamento da notícia, ao passo que o plano da especificação corresponde ao desenvolvimento desse informe. Representando esses dois planos na construção da interação, podese constatar que, na composição das notícias com entrevista, materializam-se sequencialmente resumo informativo de abertura (plano da sumarização) $\rightarrow$

Deve-se esclarecer que Dijk (1990, 2010) concentra-se na investigação do discurso noticioso de textos jornalísticos da imprensa escrita, particularmente os "[...] artigos jornalísticos em sentido estrito" que recobrem "acontecimentos políticos, sociais ou culturais que já tenham se realizado." (DIJK, 1990, p.18). A despeito de o presente trabalho se diferenciar do enfoque adotado por Dijk $(1990,2010)$ em razão da base empírica e do objeto de estudos, consideramos que a premissa da estruturação estratégica da notícia pode ser também verificada no domínio radiofônico, a exemplo das notícias com entrevista analisadas. Salvo quando indicado nas referências, todas as traduções livres utilizadas neste artigo são de responsabilidade do autor da pesquisa. 
entrevista (plano da especificação) $\rightarrow$ resumo informativo de fechamento (plano da sumarização).

O resumo informativo de abertura corresponde a uma orientação temática global sobre a notícia, fornecendo ao rádio-ouvinte as instruções essenciais não apenas para que se inteire do que será informado, mas sobretudo para localizá-lo junto à situação de interação, oferecendo-lhe coordenadas necessárias para a construção do sentido a partir das informações que serão noticiadas. O excerto destacado entre chaves em (5), a seguir, constitui um resumo informativo de abertura. Apenas depois dessas instruções, a entrevista efetivamente se inicia:

(5) \{ S.S: agora em Rio Preto quatro horas e vinte e nove minutos.. quatro e vinte nove na cidade... nós vamos conversar a partir de agora com $S$. P... presidente do Sindicato dos Empregados em Turismo e Hospitalidades... já:: que: temos que saber aí os trabalhadores querem saber como estão as negociações de duas categorias que têm como data-base primeiro DE aGOsto que são os trabalhadores em casa de diversões e também nas empresas de conservação de elevadores primeiramente S.... vamos falar sobre as negociações no setor de casas DE diversões quais as novidades? \}boa tarde $\mathrm{S}$.

S.P.: boa tarde boa tarde a todos os ouvintes da rádio Metrópole o que nós temos a dizer é que em relação aí esta categoria de casas de diversões éh:: nós tamos em negociação coletiva a convenção coletiva melhor dizendo... (JT-05:01-11)

Manifestando o plano da especificação dos acontecimentos, a entrevista funciona como uma situação interacional que detalha a informação, servindo de suporte ao informe e assegurando o desenvolvimento do tópico discursivo (JUBRAN, 2006). Nesse modo de apresentação das notícias, a entrevista concorre para a construção do efeito persuasivo da informação noticiada não apenas no sentido de que permite detalhar a informação que serve de tópico ao discurso, mas também em razão de integrar à situação de interação mais um participante, o entrevistado, a quem cabe referendar os fatos noticiados.

Operando a finalização do informe, o resumo informativo de fechamento, por sua vez, destaca informações que o locutor-entrevistador avalia como pertinentes para operar o encerramento da notícia. A depender de como a distribuição da notícia é gerenciada entre os seus planos de apresentação, o locutor-entrevistador pode não apenas fornecer ao rádio-ouvinte uma recapitulação de informações já noticiadas, mas também introduzir informações complementares. No informe JT-09, por exemplo, é somente durante o resumo informativo de fechamento, transcrito em (6), que o locutor divulga o nome do evento sobre o qual a entrevistada estava falando (o seminário "Convergindo diferenças"): 
(6) S.: conversamos aí com a D. ... éh...: A. P. ela que é primeira tesoureira da Adevir Associação dos Deficientes Visuais de Rio Preto e Região nós temos aí... uma audiência... né? temos uma boa audiência entre com os nossos amigos éh:: deficientes visuais que acompanham... né? acompanham a emoção do rádio... fica o convite feito aí pelo pessoal da Adevir Associação dos Deficientes Visuais de Rio Preto e o seminário Convergindo diferenças vai acontecer amanhã... amanhã dia vinte e seis quarta-feira a partir das duas horas da tarde das duas da tarde às seis da tarde no SENAC aqui em Rio Preto no auditório do SENAC ah:: pra quem não sabe o SENAC fica ali na rua Jorge Tibiriçá trinta e cinco dezoito no bairro... Santa Cruz próximo ali... um quarteirão pra cima da avenida... Alberto... Andaló tá bom? fica aí o convite pros nossos amigos que estão acompanhando o:: programa Jornal do Trabalhador... e também fica o convite... não somente para os portadores de deficiência visual ou deficiência motora... pra você meu amigo empresário pra você se conscientiva/ se conscientizar e ver a importância observar a importância... de abrir um espaço dentro da sua empresa para portadores de deficiência fica o recado do programa Jornal do Trabalhador... (JT-09:180-194)

Trata-se, assim, de dois planos estratégicos de realização da notícia que implicam mais que perspectivas de apresentação do informe, visto que definem a atribuição de papéis discursivos aos participantes da interlocução e revelam o gerenciamento da situação interativa. Propondo uma analogia com Dijk (1990), é possível afirmar que, da mesma maneira que a manchete e o lide ${ }^{6}$ representam a macroestrutura temática geral do artigo jornalístico e os parágrafos seguintes proporcionam especificações, o resumo informativo de abertura também deve ser representado por uma macroestrutura temática geral do que será noticiado, tendo a entrevista a função estratégica de fornecer especificações sobre o conteúdo global apresentado. O resumo informativo de fechamento, por outro lado, assemelha-se a uma paráfrase resumidora (HILGERT, 2006), evocando aquilo que Prado (1989, p.55) denomina "função da redundância", vista como essencial para reafirmar a permanência da mensagem noticiada.

Consideradas as atribuições delegadas aos participantes da interação, podemos propor que, tendo em vista os planos da sumarização e da especificação do informe, o locutor-entrevistador gerencia pelo menos quatro movimentos macroestruturais na organização discursiva das notícias com entrevista: (a) abertura do informe, (b) abertura da entrevista, (c) fechamento da entrevista $e$ (d) fechamento do informe. A depender das informações que possui e da presença virtual da audiência, o locutor-entrevistador necessariamente efetua escolhas acerca do conteúdo a ser salientado, bem como reformulações ou mesmo substituições

\footnotetext{
De acordo com teorias do jornalismo, o lide (ou lead) pode ser descrito como um conjunto de informações indispensáveis ao relato e que respondem às perguntas básicas do leitor: o quê, quem, como, onde, quando e por quê (PENA, 2005, p.41-49). Como destaca Lage (2005, p.73-74), a origem do lide reporta aos antigos relatos orais, tendo como finalidade pragmática tornar mais eficiente a veiculação de uma informação noticiada, uma vez que circunscreve os fatos em um espaço-tempo coerente.
} 
de partes do informe a ser noticiado. Visando à permanência presumida dos rádio-ouvintes na dinâmica interacional das notícias com entrevista, compete ao locutor-entrevistador, portanto, decidir pelas informações prospectivas a serem detalhadas pelo entrevistado, que, por seu lado, exerce uma função corroborante e colaboradora no projeto de dizer enunciativamente instituído.

Assim como o papel do locutor-entrevistador não pode ser dissociado de sua função de gerenciador da interação, também a atuação do entrevistado está relacionada à sua função de comentador (colaborador), a quem cabe referendar o evento noticiado. A função de colaborador, desse modo, pode apenas ser atribuída a atores sociais aptos à realização dessa tarefa. Por essa razão, nas notícias com entrevista, os entrevistados são reconhecidos representantes de diferentes associações, sindicatos, instituições, com nível superior de escolaridade. Em outros termos, desempenham um papel socioinstitucional consolidado que lhes autoriza a atuar no plano da especificação da notícia na condição de colaboradores ao desenvolvimento de um determinado projeto de dizer. Os entrevistados falam, assim, em nome de uma representação social com o intuito (i) de divulgar um acontecimento ou evento programado ou (ii) apresentar os procedimentos para executar algum serviço de interesse público.

Como destaca Dijk (1990), o discurso jornalístico vale-se de vários recursos retóricos que se destinam ao estabelecimento do efeito persuasivo das afirmações noticiadas. Visto que as proposições veiculadas devem ser avaliadas como verdadeiras pelo interlocutor, podem ser reconhecidas diversas estratégias que se destinam a promover esse efeito na construção dessas informações. No discurso noticioso com entrevista, o papel legitimador do entrevistado representa um desses recursos retóricos para acentuar a factualidade dos eventos noticiados, correspondendo ao que Dijk (1990, p.126) denomina como "[...] uso de evidência de outras fontes confiáveis (autoridades, pessoas respeitáveis, profissionais)." Conforme ressalta Dijk (1990, p.130), "[...] o fato de introduzir participantes como falantes beneficia tanto a dimensão humana dos acontecimentos informativos como a dramática."

As notícias com entrevista, nesse sentido, servem-se de diferentes recursos estratégicos que acentuam a percepção da factualidade das informações noticiadas, tais como a apresentação do informe em dois planos (a sumarização e a especificação) e a inclusão de participantes aptos a legitimar as informações. A utilização dessas diferentes estratégias de persuasão faz com que as informações veiculadas sejam vistas como proposições válidas, de modo que os eventos noticiados são, por isso, colocados na perspectiva de sua realização, favorecendo a atualização de formas de futuro perifrástico progressivo. Essas perífrases progressivas de futuro expressam um futuro presentificado decorrente da cursividade inerente que as construções verbais com formas de gerúndio carreiam. 
Como é largamente discutido na literatura, as chamadas formas nominais do verbo distinguem-se por sua oposição aspectual (CAMARA JUNIOR, 1998; ALMEIDA, 1980; entre outros). Conforme descreve Camara Jr. (1998, p.102-103), o gerúndio associa-se à imperfectividade, "ao processo inconcluso", em oposição ao particípio, vinculado à perfectividade, "aspecto concluso"; e o infinitivo apresentase como a forma indefinida do verbo, "sem implicação das noções gramaticais de tempo, aspecto ou modo". Nesse sentido, o inerente valor imperfectivo das construções em que o gerúndio intervém torna o futuro perifrástico progressivo uma forma de representar os eventos prospectivos como um estado de coisas em desenvolvimento, percebido pelo rádio-ouvinte como uma cena futura que certamente será realizada por ser gramaticalmente representada como um futuro cursivo. O uso do futuro perifrástico progressivo nas notícias com entrevista pode ser vinculado, assim, a uma função persuasiva que visa manifestar linguisticamente o caráter factível das informações veiculadas. A materialização textual dessa forma de futuro progressivo resulta, desse modo, da elaboração estratégica do discurso noticioso com entrevista. No trecho (7) a seguir, por exemplo, a pergunta do locutor-entrevistador $S$. representa um evento futuro ("entrega das carteirinhas dos sócios de um determinado sindicato") que, na dinâmica interacional das notícias com entrevista, deve ser especificado e corroborado pela entrevistada $R$., a quem cabe apresentar esse evento prospectivo como uma cena factível e, por isso, em desenvolvimento:

(7) S.: e a gente tem a informação de que possivelmente a partir da próxima seMAna essas car/ novas carteirinhas já serão entregues para o trabalhador

R.: exatamente S. éh:: na próxima semana já vai estar sendo oh:: os nossos diretores vão tá indo nas empresas pra tá entregando éh:: e também levando novas fichas né? pra pra que o trabalhadores que não não in/ não fez ainda o seu recadastramento pra que ele faça e pra q/ pra que a gente providencie as carteirinhas também pra esses trabalhadores.

S.: então é importante lembrá-los os trabalhadores não terá que ir vir a ir até a sede do sindicato... para retirar a carteirinha ela será entregue no próprio local de trabalho

R.: isso mesmo... os diretores vão tá indo até as empresas onde vão tá entregando as carteirinhas pros associados que já se recadastraram e os novos... fazendo seu recadastramento (JT-03:21-31)

Seguindo essa mesma orientação argumentativa, no segmento textual (8), a entrevistada $D$. especifica os procedimentos que precisam ser seguidos para "o agendamento de perícia médica no INSS", de maneira que as etapas desse evento prospectivo e procedimental constituem ações que necessariamente deverão ser cumpridas por aqueles que necessitam do referido serviço. Tratase de atividades que terão de ser efetuadas e, em razão dessa certeza inferida, 
favorecem construções de futuro perifrástico progressivo por serem descritas como se já estivessem acontecendo em um momento futuro ao da situação enunciativa:

(8) D.: tá... o telefone um três cinco ele serve pra fazer qualquer atendimento na previdência sobre protocolos de benefícios seja o benefício por incapacidade pra tá agendando uma perícia médica seja pra fazer um protocolo de qualquer pedido de benefício aposentadorias éh: auxílio (rescisão) salário-maternidade pensão qualquer benefício benefício assistencial se a pessoa precisar de fazer um protocolo de qualquer pedido de benefício vai ligar no um três cinco... vai... falar a cidade mais próxima de onde tá morando e vai tá agendando atendimento na agência do INSS mais próxima do seu endereço no dia e no horário agendado essa pessoa vai comparecer na nossa agência munida de todos os documentos que o um três cinco já vai tá passando a orientação pra tá fazendo o seu atendimento então isso éh:: vem de encontro àquelas pessoas que ainda acham que tem que ir cedo nas nas portas do INSS formando filas aguardando pelo atendimento não tem necessidade... liga no um três cinco agenda o dia e o horário e nesse dia nesse horário agendado basta comparecer meia hora antes do horário agendado pra tá conseguindo o seu atendimento (JT-10:72-84)

Considerando-se o arranjo interacional das notícias com entrevista em relação ao qual o locutor-entrevistador e o entrevistado desempenham papéis discursivos, é possível afirmar também que as funções desempenhadas por esses participantes favorecem determinadas formas de atualização verbal da futuridade, como se nota na tabela 2:

Tabela 2 - Distribuição relativa das formas de manifestação verbal segundo o papel desempenhado por cada participante

\begin{tabular}{lccccc}
\hline $\begin{array}{l}\text { Papéis } \\
\text { desempenhados }\end{array}$ & $\begin{array}{c}\text { ir (presente) } \\
\text { infinitivo }\end{array}$ & $\begin{array}{c}\text { ir } \begin{array}{c}\text { (presente) } \\
+ \text { gerúndio }\end{array} \\
\begin{array}{l}\text { Gerenciador } \\
\text { (locutor- } \\
\text { entrevistador) }\end{array}\end{array}$ & $\begin{array}{c}\text { presente } \\
\text { simples }\end{array}$ & $\begin{array}{c}\text { futuro } \\
\text { sintético }\end{array}$ & Total \\
$\begin{array}{l}\text { Colaborador } \\
\text { (entrevistado) }\end{array}$ & $87(68 \%)$ & $8(7,5 \%)$ & $19(17 \%)$ & $8(7,5 \%)$ & 110 \\
\hline
\end{tabular}

Fonte: Elaboração própria.

Por meio da tabela acima, pode-se identificar a distribuição percentual da futuridade verbal relativa aos papéis atribuídos ao locutor-entrevistador e ao 
entrevistado. Proporcionalmente a cada uma das funções exercidas, observase que o locutor-entrevistador apresenta percentuais mais elevados que o

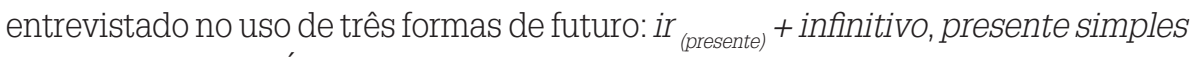
e futuro sintético. É apenas com relação à perífrase ir (presente) + estar + gerúndio que o entrevistado apresenta um percentual proporcionalmente mais expressivo que o locutor-entrevistador.

Essa constatação reafirma a função legitimadora do entrevistado, a quem compete respaldar as informações noticiadas, apresentando-as da perspectiva de sua realização, sendo, nesse caso, gramaticalmente marcadas por formas perifrásticas progressivas de futuro. Por meio dessa forma verbal, os eventos prospectivos são discursivamente concebidos como se fossem ações ou cenas futuras presentificadas, dada a intensificação da factualidade das informações veiculadas nas notícias com entrevista.

\section{Os eventos prospectivos noticiados e a distribuição das formas de futuridade}

Em vista do funcionamento organizacional das notícias com entrevista, é possível propor ainda uma descrição da distribuição discursiva e situada da futuridade de acordo com os tipos de eventos prospectivos veiculados. Tradicionalmente, as classificações elaboradas para o futuro do presente respaldam-se em critérios sintático-semânticos, dada a grande maleabilidade e oscilação modal e temporal da futuridade (FLEISCHMAN, 1982a). No entanto, acreditamos que também é pertinente representar as distinções entre as formas de futuridade em termos da funcionalidade das informações que integram na dimensão discursiva das notícias com entrevista. Nossa proposta decorre das diferentes funções que a futuridade desempenha na dinâmica interacional dos informes em termos da natureza dos eventos prospectivos que são noticiados. É possível identificar, nesse sentido, três tipos de eventos prospectivos que permitem caracterizar discursivamente a contribuição da futuridade na construção enunciativa das notícias com entrevista: 
Quadro 1 - Tipos de eventos prospectivos nas notícias com entrevista

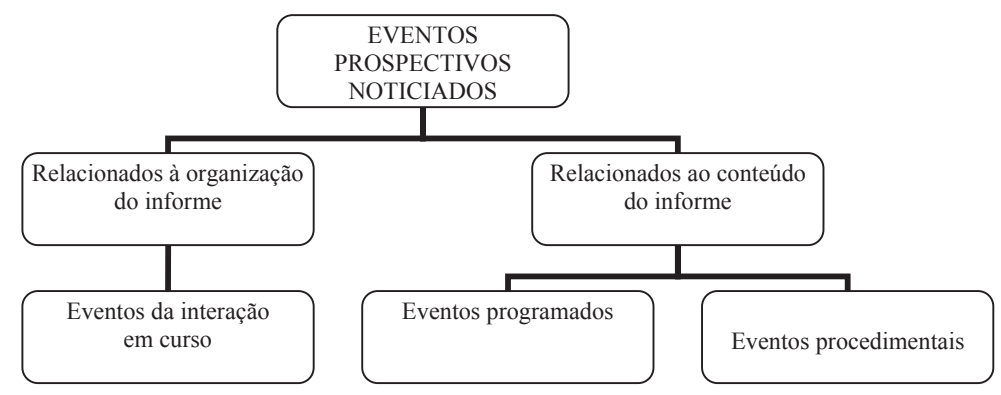

Fonte: Elaboração própria.

Novamente, essa divisão dos eventos reflete a construção da dinâmica interacional pela atribuição de papéis aos participantes das notícias com entrevista. Os "eventos da interação em curso" definem-se pela atuação gerencial da notícia, ao passo que os "eventos programados" e os "eventos procedimentais" relacionam-se ao conteúdo da informação noticiada e são legitimados pela função de colaborador do entrevistado. Na distribuição geral desses eventos em vista do total de manifestações verbais do futuro do presente (260 ocorrências), os eventos programados são o tipo mais frequente (193/74\%), seguidos pelos da interação em curso (35/14\%) e pelos procedimentais (32/12\%) (eventos programados > eventos da interação em curso > eventos procedimentais). O fato de os eventos programados serem mais recorrentes transparece fundamentalmente a natureza das informações noticiadas, uma vez que grande parte dos informes refere-se a acontecimentos programados que se realizariam num intervalo de tempo próximo ao da veiculação das notícias com entrevista.

No funcionamento interacional do discurso, os eventos programados definem-se pela natureza planejada que caracteriza o conteúdo das proposições futuras noticiadas. Tendem a vir acompanhados de adjuntos adverbiais que os localizam em relação a alguma coordenada temporal exterior à interação, que pode ser expressa ou inferível pelo contexto, como "hoje", "amanhã", "sexta-feira", "na próxima semana", etc. Dada a significativa recorrência desse tipo de evento, nele se atualizam as quatro formas de expressão da futuridade nas notícias com entrevista. Constatamos, entretanto, que o presente simples e o futuro sintético ocorrem quase sempre em vinculação com esse tipo de evento, conforme ilustram as duas ocorrências a seguir:

(9) fica o convite então... pra você meu amigo servidor você minha amiga servidora estar participando do lançamento do livo do livro As dúvidas mais frequentes sobre previdência própria que acontecerá amanhã... acontece amanhã às sete e meia da noite lá... no clube do lago tá? (JSPM-05:35) 
(10) J.: amanhã a:: às dezoito e trinta a primeira convocação e dezoito e quarenta e cinco a segunda

S.: será no próprio conselho municipal de saúde?

J.: será no próprio conselho municipal de saúde (JT-02:80-81)

Já os eventos da interação em curso referem-se àquelas proposições que noticiam o ato comunicativo em desenvolvimento, fazendo menção à organização diretiva da notícia com entrevista gerenciada pelo locutor-entrevistador. Em outros termos, constituem segmentos da notícia que comunicam as ações que deverão ser praticadas em sua realização. São acompanhados por adjuntos adverbiais que localizam o evento na própria interação, como "neste programa", "agora", "daqui a pouco no programa", e revelam a perspectiva autorreflexiva ou metadiscursiva (BORILLO, 1985; JUBRAN, 2005, 2009) da interlocução verbal. Por meio desses eventos, estabelece-se uma ligação entre a informação noticiada e o "agora" (o discurso noticioso como realidade interacional). Caracterizam-se pelo uso recorrente de "verbos de comunicação", que designam a atividade metadiscursiva, tais como "conversar", "falar", "saber" (= informar-se), "fazer o convite" (= convidar), etc.

Verificamos que, nesse tipo de evento, a futuridade verbal é quase sempre atualizada pela perífrase ir (presente) + infinitivo. Entendemos que o fato de os eventos da interação em curso atualizarem a expressão da futuridade preferencialmente por esse tipo de perífrase justifica-se em razão da "relevância do presente" (FLEISCHMAN, 1982a, 1982b, 1983) ${ }^{7}$ que caracteriza essa forma de futuridade. No trecho (11), por exemplo, notamos que o segmento em itálico refere-se ao próprio informe como evento comunicativo, revelando na fala do locutor-entrevistador $S$. a estruturação interacional e tópica do texto:

(11) S.: aproveitando também a oportunidade já que nós estamos falando aí com a advogada do sindicato a doutora R. C. S. vamos falar um pouquinho sobre a questão do atendimento jurídico como funciona o atendimento jurídico pro nosso amigo trabalhador e:: qual o horário de atendimento da assessoria jurídica do sindicato

R.: éh:: a assessoria jurídica tá aqui à disposição de todos os trabalhadores ((ruídos indistintos ao fundo)) pra qualquer dúvida qualquer esclarecimento ((ruídos indistintos ao fundo)) éh:: éh:: no período da manhã e no período da tarde

De acordo com Fleischman (1982a, 1982b, 1983), a noção de "relevância do presente" ou "aspecto prospectivo" pode ser definida como um valor pragmático-discursivo e também psicológico (por sua vinculação à perspectiva assumida pelo falante) que permite caracterizar o perifrástico formado pelo verbo ir (presente) + infinitivo (qualificado genericamente de go-future). Por meio da relevância do presente, estabelece-se uma ligação entre o "agora" e o "não agora" do presente do falante. O evento futuro, nesses casos, é percebido como uma realização que procede das circunstâncias presentes, é determinado por essas circunstâncias ou, ainda, depende do momento presente. 
também... no período da manhã das oito ao meio dia e à tarde das quatorze às dezoito horas (JT-03:32-39)

Já os eventos procedimentais localizam o evento prospectivo como parte de um "contexto injuntivo". Diferentemente dos eventos programados (planejados para ocorrer numa data próxima à da transmissão da notícia) e dos eventos da interação em curso (previstos para acontecer no desenvolvimento da notícia), os eventos procedimentais não apresentam uma ancoragem pontual necessariamente estipulada. Nesse sentido, o evento prospectivo procedimental integra um ato de fala que determina uma forma de fazer, em que são oferecidas instruções que poderão ser seguidas (CINTRA, 2011). O segmento (12), por exemplo, insere-se num momento da notícia, em que se destaca o modo de agir caso haja interesse na contratação de um seguro de vida de uma determinada empresa de São José do Rio Preto:

(12) qualquer dúvida meu amigo servidor é só ligar no três dois três quatro dez zero quatro... três dois três quatro dez zero quatro que as funcionárias do sindicato vão estar... entrando em contato com o Joel e o Joel vai estar visitando 0 seu local de trabalho (JSPM-04:59-60)

A análise dos dados indica que, dentre as quatro formas de expressão verbal do futuro do presente, nos eventos prospectivos procedimentais foram atualizadas apenas as formas perifrásticas ir (presente) + infinitivo e ir ${ }_{\text {(presente) }}+$ estar + gerúndio.

Nota-se, dessa maneira, que a natureza da informação prospectiva noticiada é fator relevante na distribuição das formas de futuridade na materialidade textual nas notícias com entrevista. Para ilustrar essa distribuição, propomos a tabela seguinte:

Tabela 3 - Distribuição relativa dos tipos de evento segundo as formas de manifestação verbal

\begin{tabular}{lcccc}
\hline \multirow{2}{*}{ Formas de manifestação } & & Tipos de evento & Total \\
& Programados & Interação em curso & Procedimentais \\
ir $_{(\text {presente) }}+$ infinitivo & $106(66 \%)$ & $33(20 \%)$ & $23(14 \%)$ & 162 \\
ir $_{\text {(presente) }}+$ estar + gerúndio & $41(80 \%)$ & $1(2 \%)$ & $9(18 \%)$ & 51 \\
presente simples & $30(100 \%)$ & - & - & 30 \\
futuro sintético & $16(94 \%)$ & $1(6 \%)$ & - & 17 \\
\hline
\end{tabular}

Fonte: Elaboração própria. 
Por meio da tabela 3, podemos observar o valor relativo do tipo do evento em cada uma das quatro formas de manifestação da futuridade. Como se nota, com exceção dos eventos programados, que não parecem desfavorecer nenhum dos quatro tipos de expressão verbal da futuridade, os dados permitem afirmar que os eventos da interação em curso e os eventos procedimentais não são propícios a determinados modos de manifestação do futuro verbal. Considerando-se esses dados sob uma perspectiva complementar, podemos propor também uma distribuição relativa das formas de expressão da futuridade especificamente de acordo com cada um dos tipos de evento, conforme exposto na tabela 4:

Tabela 4 - Distribuição relativa das formas de manifestação segundo os tipos de evento

\begin{tabular}{lccccc}
\hline \multicolumn{5}{c}{ Formas de manifestação } \\
Tipos de eventos & $\begin{array}{c}\text { ir (presente) } \\
\text { infinitivo }\end{array}$ & $\begin{array}{c}\text { ir }_{\text {(presente) }}+ \\
\text { estar+geníndio }\end{array}$ & $\begin{array}{c}\text { presente } \\
\text { simples }\end{array}$ & $\begin{array}{c}\text { futuro } \\
\text { sintético }\end{array}$ & Total \\
Programados & $106(55 \%)$ & $41(21 \%)$ & $30(16 \%)$ & $16(8 \%)$ & 193 \\
Interação em curso & $33(94 \%)$ & $1(3 \%)$ & - & $1(3 \%)$ & 35 \\
Procedimentais & $23(72 \%)$ & $9(28 \%)$ & - & - & 32 \\
\hline
\end{tabular}

Fonte: Elaboração própria.

A tabela 4 permite observar, percentualmente, a distribuição de cada uma das quatro formas de expressão da futuridade em relação ao tipo de evento prospectivo que caracteriza discursivamente a futuridade na dimensão enunciativa das notícias com entrevista. Como se nota, o percentual mais significativo de cada uma das formas de manifestação do futuro do presente ocorre nos eventos programados. Como descrito anteriormente, os programados podem ser considerados os eventos prospectivos prototípicos das notícias com entrevista, devido à própria natureza dos informes divulgados nesse gênero. Esse fato certamente explica o elevado número de ocorrências de futuridade, nas quatro formas de manifestação, que nesse tipo de evento se materializam.

Os eventos da interação em curso, por outro lado, favorecem amplamente

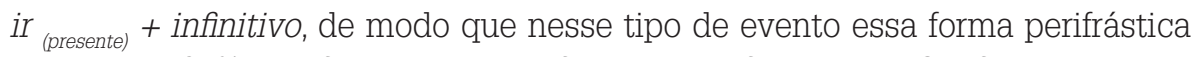
representa 94\% das formas de manifestação da futuridade. Conforme exposto anteriormente, a autorreferencialidade discursiva característica desse tipo de evento vincula-se à "relevância do presente" (FLEISCHMAN, 1982a, 1982b, 1983) que marca essa forma perifrástica. Quanto aos eventos procedimentais, foi possível constatar que propiciam apenas ocorrências perifrásticas de futuridade, 


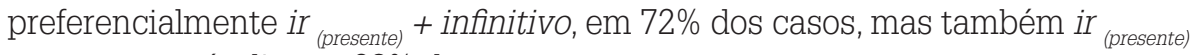
+ estar + gerúndio, em 28\% dos casos.

Podemos concluir, desse modo, que a distribuição das formas de futuro pode ser vinculada a eventos discursivos que permitem descrever o funcionamento enunciativo das notícias com entrevista. Em outros termos, podemos afirmar que, na atualização discursiva da futuridade pelas formas verbais, é possível reconhecer a influência da elaboração estratégica do gênero que as instancia.

\section{Considerações finais}

Embora sejam poucas as propostas de orientação textual para o tratamento da futuridade, não poderíamos encerrar este artigo sem fazer referência a duas delas, para que nossa abordagem possa ser situada relativamente a outras de natureza afim. Nesse sentido, deve-se destacar o trabalho de Ademar da Silva (2002) acerca da expressão da futuridade no português falado, por distinguir-se de outros estudos ao integrar argumentos de ordem textual e discursiva à descrição das formas verbais do futuro. O autor, no entanto, não enfatiza a vinculação das construções verbais ao gênero em que se materializam e tampouco propõe uma distribuição das formas de futuro de acordo com a dinâmica interacional das situações de interlocução que investiga. Devemos mencionar também a proposta do estruturalista Harald Weinrich (1974) que, visando à composição de uma gramática do texto, procura estabelecer uma caracterização textual como forma de divisão do sistema verbal. Weinrich (1974) correlaciona a distribuição dos tempos verbais à atitude comunicativa do falante, que se revela mais tensa e comprometida na situação comunicativa comentadora (comentário) e mais descompromissada na situação comunicativa narrada (narração) (WEINRICH, 1974; CINTRA, 2011).

Diferentemente dos estudos de Ademar da Silva (2002) e de Weinrich (1974), entretanto, a proposta de análise aqui apresentada circunscreve-se ao gênero notícia com entrevista e procura descrever as formas verbais do futuro a partir da articulação com o funcionamento estratégico desse tipo de discurso noticioso do domínio radiofônico. A pressuposição de que as notícias com entrevista são estrategicamente elaboradas implica não apenas que a forma de apresentação das informações é esquematicamente concebida para favorecer a interação, mas também que essa estruturação discursiva motiva a elaboração linguística do conteúdo da informação, como atestado pelas construções de futuro perifrástico progressivo. Conforme discutido, devido à imperfectividade aspectual inerente às construções verbais em que intervêm formas de gerúndio, as perífrases progressivas de futuro representam os estados de coisas como um futuro em desenvolvimento, projetado no discurso como uma cena factível e, por isso, passível 
de presentificação. A manifestação textual dessa forma de futuro progressivo é resultante, por sua vez, do funcionamento estrategicamente elaborado do discurso noticioso com entrevista. A função legitimadora do entrevistado está diretamente relacionada à expressão do futuro perifrástico progressivo, uma vez que cabe a este participante da interação referendar as informações noticiadas, colocando-as na perspectiva da realização.

Procuramos mostrar também a viabilidade de se propor uma distribuição das formas de futuridade de acordo com os variados eventos prospectivos em que se materializam, ou seja, em vinculação com os eventos discursivos que caracterizam o próprio funcionamento enunciativo das notícias com entrevista de natureza prospectiva.

Ainda que seja indiscutível a relevância de se examinar o intercâmbio entre as formas verbais vinculadas ao futuro a partir de um ponto de vista sintáticosemântico, parece igualmente pertinente caracterizar a expressão da futuridade em função das relações textuais e discursivas nos gêneros em que se manifestam. Esperamos, dessa maneira, contribuir para essa discussão acerca da relação entre gênero discursivo e expressão verbal — ainda em construção na literatura sobre o assunto - mostrando que a correlação entre o discurso e a manifestação verbal é não só pertinente mas também necessária para compreender os contextos de atualização de determinadas formas de expressão da futuridade.

\section{Agradecimentos}

O autor do presente trabalho agradece o apoio financeiro da Fundação de Apoio à Pesquisa do Estado de São Paulo (FAPESP / Proc.: 2006/51932-7).

CINTRA, M. R. The relationship between genre and verbal expression: a discursive approach to the manifestation of futurity. Alfa, São Paulo, v.58, n.1, p.93-114, 2014.

- ABSTRACT: The main purpose of this paper is to describe future verb forms in articulation with the discursive functioning of the genre in which they manifest themselves. We focus on verb forms which enable the expression of present future in the news with interview radio genre. We describe the structure of this genre in terms of its strategic devices (DIJK, 1990, 2010) which aim at increasing the factual perception of broadcast information. The strategic elaboration of news with interview implies not only that the mode of presentation of information is schematically conceived in order to favor interaction, but also that such discursive structuring prompts linguistic elaboration of the information content. Our investigation enables us to observe that present future forms can be discursively described and distributed due to the three different prospective events in which they manifest themselves: scheduled events, events involving the ongoing interaction, and procedural events. Besides, the present study demonstrates the feasibility of establishing a relationship between discourse genre and verb 
expression for the reason that some forms of futurity, such as progressive periphrastic future, are favored by discursive practices, such as news with interview.

- KEYWORDS: Present Future. Discourse Genre. News with Interview.Strategic Structuring.

\section{REFERÊNCIAS}

ALMEIDA, J. L. Introdução ao estudo das perífrases verbais de infinitivo. São Paulo: ILHPA-HUCITEC, 1980.

ALMEIDA, J. L.; GERAB,W. T. L. Quo vadis, retoricidade? estratégias interacionais em entrevistas radiofônicas. In: PRETI, D. (Org.). Oralidade em diferentes discursos. São Paulo: Humanitas, 2006. p.209-242. (Projetos Paralelos, v.8).

AQUINO, Z. G. O. Cortesia e descortesia em debates radiofônicos: um estudo das seqüências indicativas de desacordo. In: PRETI, D. (Org.). Cortesia verbal. São Paulo: Humanitas, 2008. p.355-375. (Projetos Paralelos, v.9).

BALEEIRO, M. I. A. O futuro do presente do português culto falado em São Paulo. 1988. 196f. Dissertação (Mestrado em Linguística) - Instituto de Estudos da Linguagem, Universidade Estadual de Campinas, Campinas, 1988.

BORILLO, A. Discours ou métadiscours? DRLAV, Paris, n.32, p.47-61, 1985.

CAMARA JUNIOR, J. M. Estrutura da língua portuguesa. 28.ed. Petrópolis:Vozes, 1998.

CASTILHO, A. T. A gramaticalização. Estudos Lingüísticos e Literários, Salvador, v.19, p.25-64, mar. 1997.

CASTILHO, A. T.; PRETI, D. (Org.). A linguagem falada culta na cidade de São Paulo: materiais para seu estudo. São Paulo: T. A. Queiroz, 1987. (Diálogos entre dois informantes, v.2).

A linguagem falada culta na cidade de São Paulo: materiais para seu estudo. São Paulo: T. A. Queiroz, 1986. (Elocuções formais, v.1).

CINTRA, M. R. A expressão verbal da futuridade no gênero notícia radiojornalística. 2011. 225f. Tese (Doutorado em Linguística) - Instituto de Estudos da Linguagem, Universidade Estadual de Campinas, Campinas, 2011.

COUTINHO, I. L. Pontos de gramática histórica. 7.ed. Rio de Janeiro: Livro Técnico, 2005.

DIJK,T. A. Estrutura da notícia da imprensa. Tradução de Cristina Teixeira Vieira de Melo. In: Cognição, discurso e interação. 6.ed. Organização e apresentação de Ingedore Grünfeld Villaça Koch. São Paulo: Contexto, 2010. p.122-157. 
. La noticia como discurso: comprensión, estructura y producción de la información. Traducción de Guillermo Gal. Barcelona: Paidós, 1990.

DISCURSO \& GRAMÁTICA. Banco de dados corpus Discurso \& Gramática: a língua falada e escrita. Disponível em: <http://www.discursoegramatica.letras. ufrj.br>. Acesso em: 02 ago. 2007.

FLEISCHMAN, S. From Pragmatics to Grammar: Diachonic Reflections on Complex Pasts and Futures in Romance. Lingua, Amsterdam, v.60, n.2/3, p.183-214, jun./ jul. 1983.

The Future in Thought and Language: Diachronic Evidence From Romance. Cambridge: Cambridge University Press, 1982a.

The Past and the Future: Are They Coming or Going? In: ANNUAL MEETING OF THE BERKELEY LINGUISTICS SOCIETY, 8., 1982, Berkeley. Proceedings... Berkeley: Berkeley Linguistic Society, 1982b. p.322-334.

GONÇALVES, S. C. L. Banco de dados Iboruna: amostras do português falado no interior paulista. 2007. Disponível em <http://www.iboruna.ibilce.unesp.br>. Acesso em: 22 out. 2009.

HILGERT, J. G. Parafraseamento. In: JUBRAN, C. C. A. S.; KOCH, I. G. V. (Org.). Gramática do português culto falado no Brasil: a construção do texto falado. Campinas: Ed. da UNICAMP, 2006. p.275-299.

HOPPER, P. J. On Some Principles of Grammaticalization. In: TRAUGOTT, E. C.; HEINE, N. (Ed.). Approaches to Grammaticalization. Amsterdam: John Benjamins, 1991. p.17-35. (Theoretical and Methodological Issues, v.1).

JUBRAN, C. C. A. S. O metadiscurso entre parênteses. Estudos Linguísticos, São Paulo, v.38, n.3, p.293-303, set./dez. 2009.

. Tópico discursivo. In: JUBRAN, C. C. A. S.; KOCH, I. G. V. (Org.). Gramática do português culto falado no Brasil: a construção do texto falado. Campinas: Ed. da UNICAMP, 2006. p.89-132.

. Especificidades da referenciação metadiscursiva. In: KOCH, I. V.; MORATO, E. M.; BENTES, A. C. (Org.). Referenciação e discurso. São Paulo: Contexto, 2005. p.219-263.

KLAUSENBURGER, J. Grammaticalization: Studies in Latin and Romance Morphosyntax. Amsterdam: John Benjamins, 2000.

LAGE, N. O texto das notícias impressas. In: Teoria e técnica do texto jornalístico. Rio de Janeiro: Elsevier: Campus, 2005. p.73-86. 
OLIVEIRA, J. M. O futuro da língua portuguesa ontem e hoje: variação e mudança. 2006. 254f. Tese (Doutorado em Língua Portuguesa) - Faculdade de Letras, Universidade Federal do Rio de Janeiro, Rio de Janeiro, 2006.

PENA, F. Teoria do jornalismo. São Paulo: Contexto, 2005.

PINHEIRO, N. F. A noção de gênero para análise de textos midiáticos. In: MEURER, J. L.; MOTTA-ROTH, D. (Org.). Gêneros textuais e práticas discursivas: subsídios para o ensino da linguagem. Bauru: EDUSC, 2002. p.259-290.

POPLACK, S.; MALVAR, E. Elucidating the Transitional Period in Linguistic Change: the Expression of the Future in Brazilian Portuguese. Probus, Dordrecht, v.19, p.121-169, 2007.

PRADO, E. Estrutura da informação radiofônica. Tradução de Marco Antônio de Carvalho. São Paulo: Summus, 1989.

SANTOS, P. T. A. Só um instante, senhora, que eu vou tá verificando se o livro tá disponível na editora: gerundismo, preconceito e expansão da mudança. 2008. 123f. Dissertação (Mestrado em Linguística) - Instituto de Letras, Universidade de Brasília, Brasília, 2008.

SILVA, A. A expressão da futuridade no português falado. Araraquara: Laboratório Editorial FCL/UNESP, 2002.

SILVA, M. A. O processo de gramaticalização do verbo ir. 2000. 142f. Dissertação (Mestrado em Linguística) - Centro de Ciências Humanas, Letras e Artes, Universidade Federal do Rio Grande do Norte, Natal, 2000.

SILVA, R. V. M. e. O português arcaico: fonologia, morfologia e sintaxe. São Paulo: Contexto, 2006.

TENANI, L. E.; GONÇALVES, S. C. L. Manual do Sistema de Transcrição de Dados - Projeto ALiRP (Amostra Linguística de Rio Preto). Instituto de Biociências, Letras e Ciências Exatas, Universidade Estadual Paulista, São José do Rio Preto, 2003. Não publicado.

WEINRICH, H. Estructura y función de los tiempos en el lenguaje. Madrid: Editorial Gredos, 1974.

Recebido em setembro de 2012.

Aprovado em fevereiro de 2013. 